\title{
Uterin Karsinosarkomlarda İmmunohistokimyasal Olarak C-KIT Ekspresyonunun Değerlendirilmesi
}

Immunohistochemical Evaluation of C-KIT Expression in Uterine Carcinosarcomas

\section{Ecmel Ișı KAYGUSUZ ${ }^{1}$}

1. Zeynep Kamil Kadın ve Çocuk Hastalıkları Eğitim ve Araştırma Hastanesi, Patoloji Bölümü, İstanbul

\section{$\ddot{O Z Z E T}$}

Amaç: Karsinosarkom oldukça agresif bir neoplazmdır. KIT-pozitif neoplazmlarda tirozin kinaz inhibitörleri tedavide başarll sonuçlar vermektedir. Bu nedenle, bu tümörlerde c-kit ekspresyonu klinik açıdan önemli olabilir. Bu çalışmanın amacı, karsinosarkomun karsinomatöz ve sarkomatöz komponenetlerinde c-kit ekspresyonunu incelemek ve bu neoplazmlarda KIT'in terapötik bir hedef olarak kullanılabilirliğini saptamaktır.

Gereç ve Yöntem: Karsinosarkom tanısı almış 20 uterusa ait parafine gömülü bloklara immunohistokimyasal olarak c-kit boyaması uygulandı.

Bulgular: Karsinosarkomlarin stromal komponentlerinde immunohistakimyasal olarak c-kit boyanan hücre saptanmad, ve epitelyal komponenette ise 9 olguda c-kit boyaması mevcuttu.

Sonuç: Sonuçlar c-kit'in bu tümörlerin karsinogenezinde muhtemelen major bir rol oynamadığını destekler görünmektedir. Tartışmalı konuları açıklığa kavuşturmak için geniş serilerle yapilacak c-kit ekspresyonunu belirleyecek yeni çalışmalar gerekmektedir.

Anahtar Kelimeler: uterus, karsinosarkom, c-kit, immünohistokimya

\footnotetext{
İletişim Bilgileri:
}

Sorumlu Yazar: Ecmel Işık KAYGUSUZ

Yazışma Adresi: Zeynep Kamil Kadın ve Çocuk Hast. Eğt. ve Arş. Hast., Patoloji Bölümü, İstanbul, Türkiye E-mail: ecmeli@yahoo.com

Makalenin Geliş Tarihi: 10.12.2014

Makalenin Kabul Tarihi: 05.04.2015

DOI: http://dx.doi.org/10.16948/zktb.00912

\section{ABSTRACT}

Objective: Carcinosarcoma is a very aggressive neoplasm. The use of tyrosine kinase inhibitors has resulted in successful treatment of KIT-positive neoplasms. Consequently, c-kit expression may have significant clinical implications for this tumor. The purpose of the present study was to assess c-kit expression in the carcinomatous and sarcomatous component of carcinosarcoma and to identify if KIT represents a therapeutic target for treatment of this neoplasm.

Material and Method: Immunohistochemical staining for c-kit was performed on paraffin-embedded tissue blocks of 20 uterine specimens with carcinosarcoma.

Results: In the stromal component of carcinosarcoma, no immunohistochemically c-kit stained cells were observed and in the epithelial component, c-kit staining was present in 9 cases.

Conclusion: The results seem to suggest that c-kit probably plays no major role in the carcinogenesis of the majority of these tumors. Further studies of c-kit expression in larger series of carcinosarcomas must be studied in order to clarify the controversial issues.

Keywords: uterus, c-kit, carcinosarcoma, immunohistochemistry 


\section{GİRIŞ}

C-kit transmembran tirozin kinaz reseptörünü olan KIT'i kodlayan bir proto-onkogendir $(1,2)$. İnsanlarda kromozom 4'ün q11-q12 alanında lokalize olur (3). KIT, bazı hücrelerde sinyal iletiminin düzenlenmesinde rol alır ve ligandı bağlandığında aktive olur. Bu aktivasyon apoptoz, hücre diferansiyasyonu, proliferasyon, kemotaksis ve hücre adezyonunu düzenler. KIT bağımlı hücreler, mast hücreleri, bazı hematopoietik sistem hücreleri, melanositler, gastrointestinal kanalın Cajal hücreleri ve bu hücrelerin KIT pozitif tümörleridir. Diğer KIT pozitif normal hücreler, deri eklerinin epitelyal hücreleri, meme duktus epitel hücreleri ve serebellar nöron alt tipleridir (4). Özellikle hematolojik proliferatif hastalıklar ve gastrointestinal stromal tümör (GIST) hücrelerinde, KIT aktivasyonuna yol açan ve c-kit'in dizilimini tamamlayan DNA'da siklikla somatik mutasyonlar bulunur. KIT'deki bu aktivasyonu kontrolsüz hücre proliferasyonuna ve apopitoza karş1 dirence neden olmaktadır (5-7). Protein kinaz aktivitesindeki düzenin bozulması insan malignitelerinde önemli rol oynamaktadır. KIT-pozitif hematolojik maligniteler ve GIST'de tirozin kinaz inhibitörleri ile yapılan tedavilerde başar1lı sonuçlar elde edilmiştir (7-11). Bu nedenle c-kit klinikte de önemli rol oynayabilmektedir.

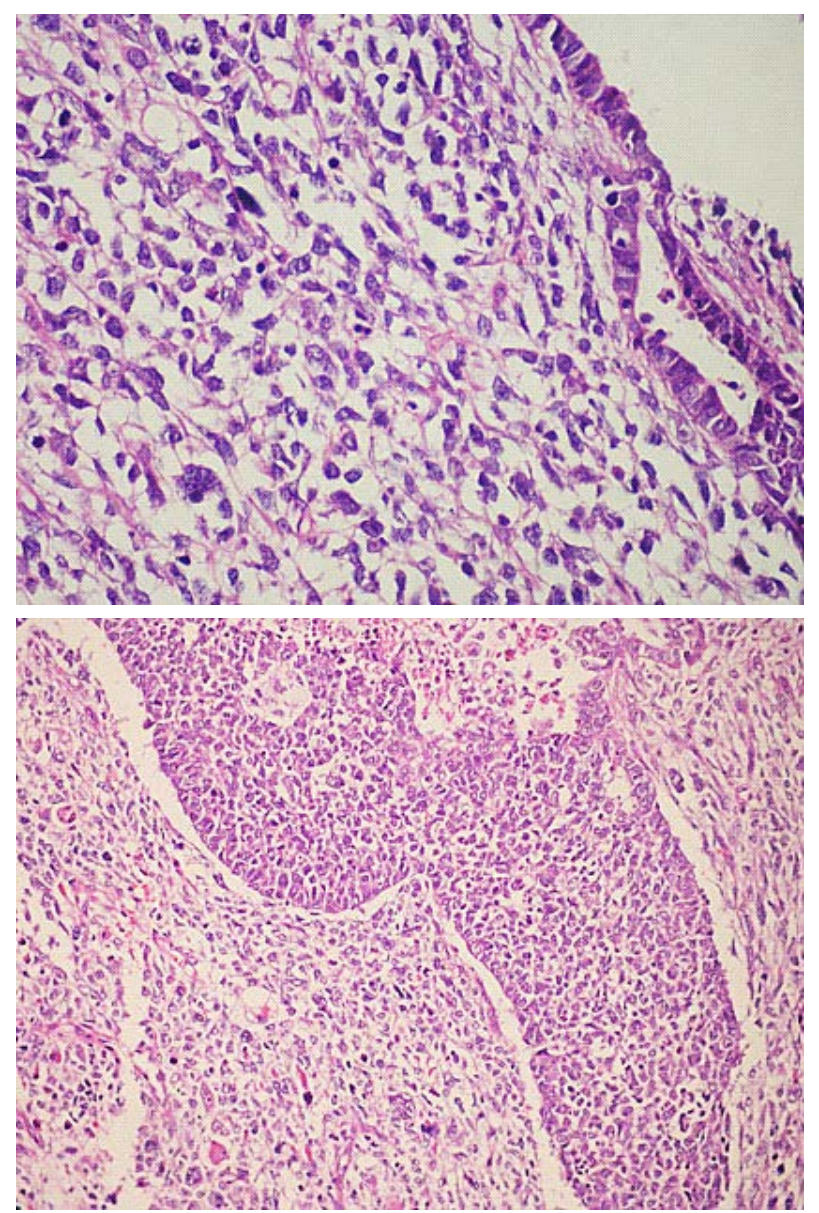

Resim 1-2: Malign histolojik bulgular tasıyan mezenkimal komponent komşuluğunda karsinom alanları. (HEX200).
C-kit çeşitli jinekolojik tümörlerde daha önce değerlendirilmiștir (12-22). Ancak endometriyal karsinosarkomlardaki sonuçlar birbirleriyle bağdaşmamaktadır. Karsinosarkomlar oldukça agresif neoplazmlar olup, kötü prognoz ve tedaviye yeterince yanit vermemeleri ile karakterlidirler. Malign özelliklere sahip epitelyal ve mezenkimal komponent içermektedirler (Resim 1-2). Tanı anında yalnızca \%45'inde uterusta sinırlı olarak izlenirler ve median sürvileri 21 aydır (23). Bu çalışmanın amacı, karsinomun her iki komponentinde de c-kit'in immunohistokimyasal ekspresyonunu ortaya koymak ve bu neoplazm için tedavide KIT'in terapötik olarak anlam ifade edip etmeyeceğini saptamaktır.

\section{GEREÇ ve YÖNTEM}

Zeynep Kamil Kadın ve çocuk hastalıkları hastanesinde patoloji bölümünde tanı alan 20 adet hastanın parafin bloklara gömülü dokuları çalışıldı. Tüm klinikopatolojik veriler patoloji arşivinden elde edildi. Hemotoksilen-eozin boyalı preperatlar tekrar değerlendirildi ve her iki komponenti (epitelyal karsinomatöz, stromal sarkomatöz) de içeren bloklara c-kit boyaması immunohistokimyasal olarak uyguland1. İmmunohistokimyasal boyama için alınan 5 mikron kalınlığındaki kesitler etüvde deparafinizasyon için 70 derecede ve 45 dakika bekletildi. Daha sonra ksilene alınan kesitler 30 dakika etüvde ve etüvden çıkarılarak oda 1sısında 10 dakika bekletildi. Deparafinizasyon sonrasi sirasiyla alkollerden (\%100 ve \%95'lik) geçirilerek distile suda yıkand1. \% 10'luk sitratta $(\mathrm{pH} \mathrm{6)}$ düdüklü tencerede kaynatıltı daha sonra soğuması beklendi. Hidrojen peroksit (\%3) damlatılarak 15 dakika tutuldu. Kesitler PBS (fosfat baffer saline) solüsyonu $(\mathrm{pH} 7,4)$ ile yıkandı ve zemin boyamasını engelleyen süperblokda 10 dakika muamele edildi. Süperblok uzaklaştırıldıktan sonra primer antikorlar (CD117/c-KIT: Biocare Medical, CA, USA) damlatıldı. Antikorlar 2 saat tutulduktan sonra TBS ile y1kanarak biotin damlatıld 1 ve 15 dakika tutuldu. Tekrar TBS ile y1kanan kesitlere HRP (horse redish peroksidaz) damlatılarak 15 dakika beklendi. TBS ile son kez yıkanarak DAB (Diaminobenzen) kromojen ile 10 dakika süreyle uygulandı. Musluk suyundan geçirilen kesitler zit boyama için hemotoksilene alındı. İmmunohistokimyasal olarak boyanan kesitler 10 büyük büyültme alanında, her kesitte minimum 1000 hücre sayllacak şekilde incelendi. Hücre memran bayanması pozitif olarak kabul edildi. Pozitif kabul edilen hücrelerin tümördeki yüzdesi verildi. Boyanmanın şiddeti 0-3 arasında skala oluşturularak değerlendirildi. "0" hiç bir boyanma elde edilmeyen örneklere, " 3 " ise en şiddetli boyanmalara kullanıldı. 


\section{BULGULAR}

Karsinosarkom tanıs1 alan olgularımızın ortalama yaşı 65 idi. 12 olgumuz stage I iken, 8 olgumuz stage II-IV idi. Olgularımızn 15 tanesinde homolog, 5 tanesinde heterelog elementler mevcuttu. Klinikopatolojik bulgular Tablo 1.'de gösterilmiştir.

Tablo 1. Uterin karsinosarkomların klinik ve patolojik bulguları.

\begin{tabular}{|l|c|}
\hline Toplam sayı & 20 \\
\hline Ortalama yaş & 65 \\
\hline Ortalama boyut (cm) & 7.3 \\
\hline Myometriyal invazyon yok & 1 \\
\hline Myometriyal invazyon (1/2 iç) & 9 \\
\hline Myometriyal invazyon (1/2 dış) & 10 \\
\hline Polip üzerinde gelişme & 2 \\
\hline Polipoid gelişme & 11 \\
\hline Stage I & 8 \\
\hline Stage II-IV & 12 \\
\hline
\end{tabular}

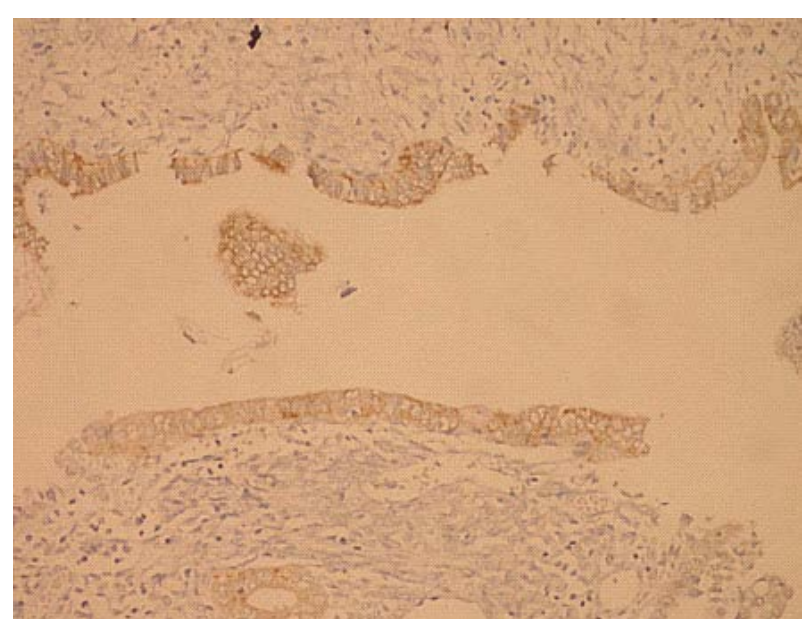

Resim 3: İmmunohistokimyasal olarak C-kit ile \%10'un üstünde boyanma gösteren epitelyal komponent ile boyanma saptanmayan mezenkimal komponent (X200).

İmmunohistokimyasal olarak karsinosarkomun stromal elementlerinde c-kit boyanması saptanmazken, epitelyal komponentte pozitiflik için kullanılan kriterlere göre $\% 10$ ve üstünde boyanma gösteren 4 (Resim 3), \%30 ve üstünde boyanma gösteren $4, \% 50$ ve üstünde boyanma gösteren 2 olgu tespit edildi (Resim 4).

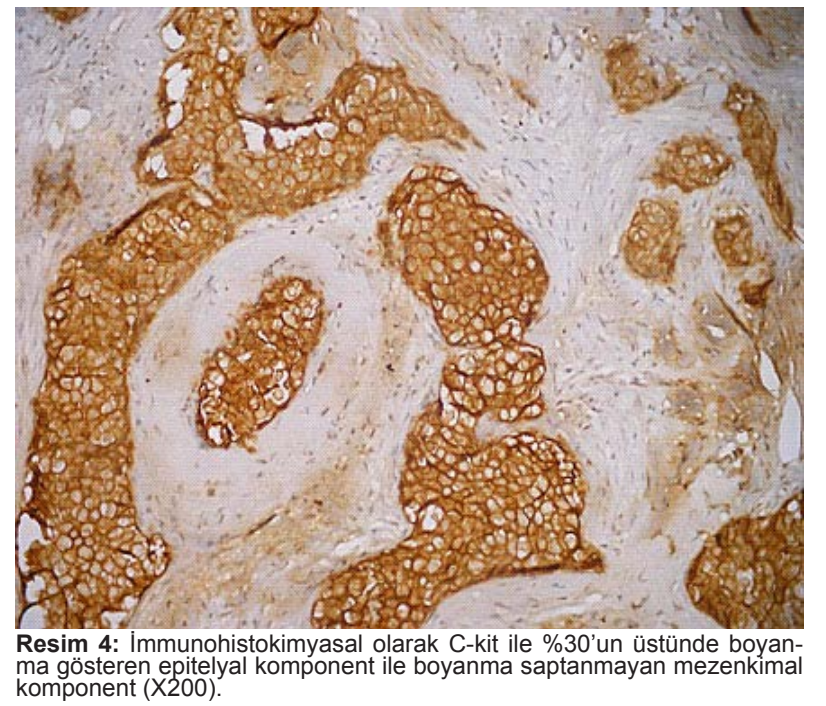

Hiç bir olguda yüksek boyanma șiddetini gösteren 2-3 şiddetinde boyanma tespit edilemedi. Pozitiflik saptanan olgularda hafif (1 şiddetinde) boyanma tespit edildi. İmmunohistokimyasal boyanma sonuçları Tablo 2.'de gösterilmiştir.

Tablo 2. Uterin Karsinosarkomlarda c-kit ekspresyonu.

\begin{tabular}{|c|c|c|c|c|}
\hline & \multicolumn{2}{|c|}{$\begin{array}{c}\text { Epitelyal } \\
\text { Komponent }\end{array}$} & \multicolumn{2}{c|}{$\begin{array}{c}\text { Sarkomatöz } \\
\text { Komponent }\end{array}$} \\
\hline Total boyanma yüzdesi & Sayı & $\%$ & Sayı & $\%$ \\
\hline$>10$ & 4 & 20 & 0 & 0 \\
\hline$>30$ & 6 & 30 & 0 & 0 \\
\hline 0 & 10 & 50 & 20 & 100 \\
\hline 1 & 10 & 50 & 0 & 0 \\
\hline 2 & 0 & 0 & 0 & 0 \\
\hline 3 & 0 & 0 & 0 & 0 \\
\hline
\end{tabular}

\section{TARTIŞMA}

Sonuçlarımıza göre sarkomatöz alanlarda c-kit pozitifliği saptanmazken, karsinom alanlarında düşük şiddet ve yüzde de olsa boyanma mevcuttu. Karsinosarkomdaki c-kit ekspresyonunu kapsayan ve daha önce yapılan kisitlı sayıdaki çalışmalarda birbirleriyle uyumlu olmayan sonuçlar elde edilmiştir (15-22). Bunlardan birinde (16) tüm tümörlerde pozitif boyanma mevcutken, diğer ikisinde $(17,18)$ hiç boyanma saptanmamıştır. Diğer çalışmalarda ise $\% 43$ ile $\% 60$ arasında değișen oranlarda pozitif boyanma bildirilmiştir. Lucas ve arkadaşlarının (24) dikkati çektiği gibi farklı ticari kuruluşlara ait boya ve boyama metodlarının kullanılması buna neden olmuş olabilir. Tablo 3 'de farklı boyanma sonucuna sahip çalışmaların özeti yer almaktadır. Diğer araștırıcıların da kullandığ 1 gibi $(21,25,26)$ biz de \%10 değerini eşik değer olarak kullandik.

Tablo 3. Önceki çalışmalarda saptanan immunohistokimysal C-kit ekspresyon oranları.

\begin{tabular}{|l|c|c|}
\hline \multicolumn{1}{|c|}{ Yazar } & Olgu sayısı & Boyanma yüzdesi \% (Sayı) \\
\hline Menczer J. & 20 & $35(7)$ \\
\hline Sawada M. & 16 & $50(8)$ \\
\hline Constantinescu M. & 25 & $100(25)$ \\
\hline Winter WE. & 21 & $43(9)$ \\
\hline Ramondetta LM. & 16 & $0(0)$ \\
\hline
\end{tabular}

Daha önce uterin leiomyosarkomlarda da c-kit ile farklı boyanmalar elde edilmiş ve bunun populasyonların farklılığından kaynaklandığ1 ileri sürülmüştür (25-29). Karsinosarkomlara ait c-kit ekspresyonunun etnisitesi önceki bir çalıșmada konu edilmiștir (15). Ancak siyah veya beyaz hastalar arasinda bir fark saptanmamıştır. Son yaklaşımlara göre karsinosarkomlar monoklonal orijinlidirler ve sarkomatöz komponentleri metaplazinin sonucudur (30). Özellikle p53 ve p27 ekspresyonunu her iki komponente de saptayan bazı çalışmalar bu 
görüșü desteklemektedirler (27, 31-33). Karsinosarkomlarda c-kit ekspresyonunu her iki komponentte de bulunan çalışmalar da aynı düsünceye sahiptir $(15,16,19,20)$. Bizim çalışmamızın sonuçlarına göre ise düşük şiddetli de olsa epitelyal komponentte saptanan c-kit pozitifliği stromal komponentte gözlemlenmemiştir. Her iki farklı komponentte saptanan bu farklı boyanma sonuçlarımız bize bu görüşün tartışmalı olduğunu düşündürmüştür. Rushing ve arkadaşlarının çalışmasına göre 14 olguluk serilerinde tüm hastlarda c-kit ekspresyonu saptanırken, bunların hiç birinde ekson 11 ve 17 mutasyon bulunmamaktadir (16). Bu nedenle, KIT-aktive edici mutasyonu bulunmayan tümörlerde trozin kinaz inhibitörlerinin tedavide aday olamayacağını düşünmüşlerdir. Ama yine de diğer mekanizmalarla da KIT aktivasyonu ortaya çıkabilir veya c-kit farklı mutasyonlar içerebilir. Ayrica c-kit'in immunohistokimyasal olarak negatif olması, gerçek negatiflik olmayabilir.

İmmunohistokimyasal çalışma kinaz aktivasyonu veya c-kit mutasyonunun varlığı için kesin tanısal değildir. Bu konudaki tartışmaları açıllayabilmek, c-kit ekspresyonu ile prognostik -terapötik değeri arasındaki ilişkiyi saptayabilmek için, geniş karsinosarkom serileriyle yapılacak ve c-kit ekspresyonunu belirleyecek çalışmalara ihtiyaç vardır.

\section{KAYNAKLAR}

1. Yarden Y, Kuang WJ, Yang-Feng T, Coussens L, Munemitsu $S$, Dull TJ, et al. Human proto-oncogene kit, a new cell surface-receptor tyrosine kinase for unidentified ligand. EMBO J 1987;6:3341- 51 .

2. Williams DE, Eisenman J, Baird A, Rauch C, Van Ness $K$, March CJ, et al. Identification of a ligand for the c-kit proto-oncogene. Cell 1990;63:167- 74.

3. d'Auriol L, Mattei MG, Andre C, Galibert F. Localization of the human c-kit protooncogene on the q11-q12 region of chromosome 4. Hum Genet 1988; 78:374 - 6 .

4. Nakata Y, Kimura A, Katoh O, Kawaishi K, Hyodo H, Abe K, et al. $C$-kit point mutation of extracellular domain in patients with myeloproliferative disorders. Br J Haematol 1995;91:6610 -30 .

5. Dudani S, Kalhan S, Sharma S, Gupta A. Gastrointestinal stromal tumours (GIST)-pathology and clinical applications of recent molecular advences-A perspective review. Çağdaş Tip Dergisi 2014;4:85-90.

6. Rubin BP, Singer S, Tsao C, Duensing A, Lux ML, Ruiz R, et al. KIT activation is a ubiquitous feature of gastrointestinal stroma. Cancer Res 2001;61(22):8118 - 21.

7. Demetri GD. Identification and treatment of chemoresistant inoperable or metastatic GIST: experience with the selective tyrosine kinase inhibitor imatinibe mesylate (STI571) Eur J Cancer 2002;38 (Suppl 5):52-59.

8. Druker BJ, Sawyers CL., Kantarjian H, Resta DJ, Reese SF, Ford JM, et al. Activity of a specific inhibitor of the BCR ABL tyrosine kinase in the blast crisis of chronic myeloid leukemia and acute lymphoblastic leukemia with the Philadelphia chromosome N Engl J Med 2001;344:1038-42.

9. DeMatteo RP. The GIST of targeted cancer therapy: a tumor gastrointestinal stromal tumor), a mutated gene (c-kit), and a molecular nhibitor (STI571) Ann Surg Oncol 2002;9:831-3.

10. Demetri GD. Targeting c-kit mutations in solid tumors: scientific rationale and novel therapeutic options. Semin Oncol 2001;28 (Suppl 17):19-26.

11. Heinrich MC., Rubin BP, Longley BJ, Fletcher JA. Biology and genetic aspects of gastrointestinal stromal tumors: KIT activation and cytogenetic alterations. Hum Pathol 2002;33:484 -95 .

12. Heinrich MC, Blanke CD, Druker BJ, Corless CL. Inhibition of KIT tyrosine kinase activity: a novel molecular approach to treatment of KIT-positive malignancies J Clin Oncol 2002;20:1692-703.

13. Elmore LW, Domson K, Moore JR, Kornstein M, Burks RT. Expression of c-kit (CD117) in benign and malignant human endometrial epithelium. Arch Pathol Lab Med 2001;125:14651.

14. Scobie JV, Acs G, Bandera CA, Blank SV, Wheeler JE, Pasha TL, et al. C-kit immunoreactivity in endometrial adenocarcinomas and its clinicopathological significance. Int J Gynecol Pathol 2003;22:149-50.

15. Alkushi A, Irving J, Hsu F, Dupuis B, Liu CL, Rijn M, et al. Immunoprofile of cervical and endometrial adenocarcinomas using a tissue microarray Virchows Arch 2003;442: 271-7. 
16. Winter WE III, Seidman JD, Krivak TC, ChauhanS, Carlson $J V$, Rose, GS et al. Clinicopathological analysis of c-kit expression in carcinosarcomas and leiomyosarcomas of the uterine corpus. Gynecol Oncol 2003;91:3-8.

17. Rushing RS, Shajahan S, Chendil D, Wilder JL, Pulliam $J$, Lee EY, et al. Uterine sarcomas express KIT protein but lack mutation(s) in exon 11 or 17 of c-KIT. Gynecol Oncol 2003;91:9-14.

18. Klein WM, Kurman RJ. Lack of expression of c-kit protein (CD117) in mesenchymal tumors of the uterus and ovary. Int. J Gynecol Pathol 2003;22:181-4.

19. Ramondetta LM, Burke TW, Jhingran A, Schmandt R, Bevers $M V$, Wolf JK, et al.A phase II trial of cisplatin, ifosfamide, and mesna in patients with advanced or recurrent uterine malignant mixed Mullerian tumors with evaluation of potential molecular targets. Gynecol Oncol 2003;90:529-36.

20. Huh WK, Conner MG, Straughn Jr. JM, Leath CA, Barnes $M N$, Alvarez RD, et al. Immunohistochemical evaluation of the $c$ Kit proto-oncogene in sarcomas of the uterus. Gynecol Oncol 2002;84:531 [abstract].

21. Constantinescu M, Turbat-Herrera EA, Nordberg ML, et al. CD117 and CD34 expression by immunohistochemistry in uterine mixed Mullerian tumors Lab Invest 2003;83:186A-7A [abstract].

22. Sawada M, Tsuda H, Kimura M, Okamoto S, Kita T, Kasamatsu T, et al. Different expression patterns of KIT, EGFR, and HER-2 (c erbB-2) oncoproteins between epithelial and mesenchymal components in uterine carcinosarcoma. Cancer Sci 2003;94:986-91.

23. Leath CA III, Straughn Jr. JM, Conner MG, Barnes III MN, Alvarez RD, Partridge EE, et al. Immunohistochemical evaluation of the c-kit proto-oncogene in sarcomas of the uterus: a case series J Reprod Med 2004;49:71-5.

24. Gadducci A, Sartori E, Landoni F, Zola P et al. The prognostic relevance of histological type in uterine sarcomas: a Cooperation Task Force (CTF) multivariate analysis of 249 cases Eur. J. Gynecol. Oncol 2002;23:295-9.

25. Lucas DR, al-Abbadi M, Tabaczka P, Hamre MR, Weaver $D W$, Mott MJ. c-Kit expression in desmoid fibromatosis. Comparative immunohistochemical evaluation of two commercial antibodies Am. J. Clin. Pathol 2003;119:339-45.
26. Wang L, Felix JC, Lee JL, Tan PY, Tourgeman DE, O'Meara $A T$, et al. The proto-oncogene c-kit is expressed in leiomyosarcomas of the uterus. Gynecol. Oncol 2003;90:402-6.

27. Miettinen M, Sobin LH, Sarlomo-Rikala M. Immunohistochemical spectrum of GISTs at different sites and their differential diagnosis with reference to CD117 (KIT). Mod. Pathol 2000;13:1134-42.

28. Abargel a, Avinoach I, Kravtsov V, Boaz M, Glezerman M, Menczer J. Expression of $p 27$ and p53: comparative analysis of uterine carcinosarcoma and endometrial carcinoma. Int. J. Gynecol. Cancer 2004;14: 354-9.

29. Bamberger A, Riethdorf L, Milde-Langosch K, Bamberger CM, Thuneke I, Erdmann I, et al. Strongly reduced expression of the cell cycle inhibitor in endometrial neoplasia Virchows Arch 1999;443:423-8.

30. Raspollini MR, Villanucci A, Amunni G, Paglierani M, TaddeiA, Taddei GL. C-kit expression in uterine leiomyosarcomas: an immunocytochemical study of 29 cases of malignant smooth muscle tumors of the uterus J. Chemother 2003;15:81-4.

31. McCluggage WG. Uterine carcinosarcomas (malignant mixed Mullerian tumors) are metaplastic carcinomas. Int. J. Gynecol. Cancer 2002;12:687-90.

32. Kounelis S, Jones MW, Papadaki P, Bakker A, Swalsky P, Finkelstein SD. Carcinosarcoma (malignant mixed Mullerian tumors) of the genital tract: comparative molecular analysis of epithelial and mesenchymal components. Hum. Pathol 1998;29:82-7.

33. Guarino M, Giordano F, Pallotti F, Polizzoti G, Tricomi P, Cristofori E. Malignant mixed Mullerian tumor of the uterus. Feature favoring its origin from a common cell clone and an epithelial to mesenchymal transformation of histogenesis. Tumori 1998;84:391-7.

34. Szukala SA, Marks JR, Burchette JL, Elbendery AA, Krigman HR. Co-expression of $p 53$ by epithelial and stromal elements in carcinosarcoma of the female genital tract: an immunohistochemical study of 19 cases. In. J. Gynecol. Cancer 1999;9:131-6.

35. Arber DA, Tamayo R, Weiss LM. Paraffin section detection of the c-kit gene product (CD117) in human tissues: value in the diagnosis of mast cell disorders Hum. Pathol 1998;29:498504. 